\title{
Surgical techniques to improve continence recovery after robot- assisted radical prostatectomy
}

\author{
Ahmet Urkmez, Weranja Ranasinghe, John W. Davis \\ Department of Urology, Division of Surgery, The University of Texas MD Anderson Cancer Center, Houston, TX, USA \\ Contributions: (I) Conception and design: All authors; (II) Administrative support: JW Davis; (III) Provision of study materials or patients: None; (IV) \\ Collection and assembly of data: None; (V) Data analysis and interpretation: All authors; (VI) Manuscript writing: All authors; (VII) Final approval of \\ manuscript: All authors. \\ Correspondence to: Dr. Ahmet Urkmez. Department of Urology, Division of Surgery, The University of Texas MD Anderson Cancer Center, 1155 \\ Pressler St, Houston, TX 77030, USA. Email: aurkmez@mdanderson.org.
}

\begin{abstract}
Radical prostatectomy directly affects urinary continence dynamics with incontinence being a major factor in patients' quality of life, social and psychological status. In order to help maintain continence after robot-assisted radical prostatectomy (RARP), a number of surgical techniques have been described. In the present narrative review, we summarize the surgical techniques that have been applied during RARP and their effects on incontinence rates and time to continence recovery.
\end{abstract}

Keywords: Continence recovery; preserving; reconstruction techniques; robot-assisted radical prostatectomy (RARP)

Submitted Oct 26, 2019. Accepted for publication Mar 11, 2020.

doi: $10.21037 /$ tau.2020.03.36

View this article at: http://dx.doi.org/10.21037/tau.2020.03.36

\section{Introduction}

Robot-assisted radical prostatectomy (RARP) is widely utilized in the treatment of prostate cancer demonstrating excellent oncological outcomes as well as functional outcomes, namely continence and erectile function (1). Continence is a major concern in patients seeking treatment for prostate cancer. According to the literature, rates of incontinence, defined as the use of at least $1 \mathrm{pad} /$ day at one year after RARP, vary from $4 \%$ to $31 \%$ (2). Postprostatectomy incontinence (PPI) also causes substantial decrease in quality of life that may manifest as preoccupation to avoid leakage, finding the location of bathrooms, and feeling dirty, weak, and ashamed (3). Various studies and systematic meta-analyses have been conducted to determine the effect of preoperative factors and intraoperative surgical techniques on post-prostatectomy continence outcomes.

The etiology of PPI is multifactorial with surgical factors playing an important role. RARPs have comparable functional outcomes to the traditional open approach with a number of advances in surgical techniques to improve continence $(2,4)$. The use of robotic surgery in radical prostatectomy has provided better visualization of apical dissection and external sphincter. In addition, surgical techniques, such as nerve-sparing and Retzius-sparing surgery, anterior and posterior reconstruction, and bladder neck preservation approaches, have improved particularly early urinary continence (5).

In the present narrative review, we summarize the surgical techniques that have been applied during RARP and their effect on incontinence rates and time to continence recovery.

\section{Methodology and literature search prioritization}

Continence sparing surgical technique is one of the most talked about subjects at professional meetings and live surgical demonstrations. The authors came up with a list of the most common "ideas" in the field and sought to match them with a literature search highlight and commentary. A review of the literature was performed using the PubMed database to identify original and review articles regarding urinary continence recovery after radical prostatectomy. The 


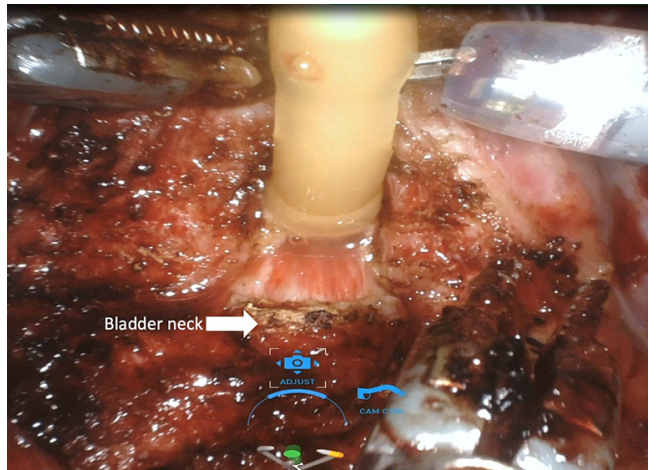

Figure 1 Bladder-neck sparing technique. Bladder-neck preservation is carried on by a combination of sharp and blunt dissection to preserve bladder neck muscle fibers.

key words included 'prostate cancer', 'neurovascular bundle', 'quality of life', 'urinary incontinence', 'robot-assisted radical prostatectomy', 'nerve-sparing', 'surgical techniques', 'bladder neck-sparing', 'Retzius-sparing', 'suprapubic tube', 'Rocco stitch', 'posterior reconstruction', 'anterior reconstruction', 'total anatomical reconstruction', 'urethral length', 'dorsal vascular complex', 'stitch', 'ligation'.

\section{Preoperative factors that affect continence rates}

Advanced age, cancer characteristics, prostate size and preoperative lower urinary tract symptoms are the main factors affecting patients' continence (6). Studies have shown that continence rates are lower in elderly patients $(7,8)$. Moreover, concomitant diseases and a high Charlson morbidity index have been reported as negative predictors of continence (9).

Other factors that may affect postoperative short- and long-term continence rates include the following: severity of preoperative lower urinary tract symptoms (10); presence of preoperative erectile dysfunction (11); preoperative membranous urethra length, measured by $\mathrm{T} 2$-weighted magnetic resonance images $(10,12)$; presence of a median lobe (13); previous transurethral resection of the prostate (14); prostate cancer treatment (15); bony pelvic dimensions (16); cigarette smoking at the time of surgery (6); and type 2 diabetes mellitus (17).

\section{Surgical factors that affect continence rates}

The experience of the surgeon has a significant effect on continence rates (18). Many studies have evaluated the impact of surgeons' experience on functional outcomes on the basis of surgeons' previous surgical outcomes, caseloads, and skills $(2,19,20)$. In a very recent prospective study, Hung et al. (21) described a new assessment tool that is used to evaluate the influence of surgeon experience on postoperative urinary continence recovery after RARP via automated performance metrics, which were derived from motion-tracking and system events data. Their findings showed that patients of surgeons who had the highest ranking of automated performance metrics reached higher continence rates at 3 and 6 months after RARP.

A number of intraoperative risk factors in PPI have been investigated. A recent systematic meta-analysis indicated that patients who underwent nerve-sparing surgery had a better post-prostatectomy continence rate for up to 6 months after radical prostatectomy compared to patients who underwent non-nerve-sparing surgery; but beyond this initial period there was no differences in continence rates between these groups (22).

In another study, Preisser et al. (23) analyzed the effect of estimated blood loss (EBL) on functional outcomes in 2,720 patients demonstrating that $\mathrm{EBL}$ of $>400 \mathrm{~mL}$ during RARP resulted in a significantly lower early continence rates (23).

\section{Surgical techniques that affect continence rates}

Radical prostatectomy disrupts the inherent anatomy of the male pelvis and the functional mechanisms of urinary continence, directly affecting the voiding dynamics. These alterations mainly result in urinary symptoms, especially stress incontinence. Therefore, to maintain continence after RARP, a number of reconstructive techniques have been described in order to mimic the original anatomy and restore function (24).

\section{Bladder neck sparing technique}

Anterior, lateral, and anterolateral approaches have been described for dissection between the bladder and prostate. Many studies have shown that protecting the bladder neck as high as possible, up to 360 degrees if possible, protects the intrinsic sphincteric mechanism and has a positive effect on continence recovery. During dissection between the bladder and prostate, utmost care should be given in order to preserve bladder neck circular fibers (Figure 1) (Video 1, both, Part-1 and 2).

The bladder neck sparing (BNS) technique in RARP 
was first described by Freire et al. (25). In this study, which included 347 patients who had undergone the BNS technique versus 271 patients who had undergone a standard RARP, Freire et al. reported significantly better continence at 4 and 12 months with BNS (65.6\% vs. 26.6\% at 4 months; $86.4 \%$ vs. $81.4 \%$ at 12 months). However, 24-month continence rates were similar for both techniques ( $100 \%$ vs. $96.1 \%, \mathrm{P}=0.308)$. In another prospective study that included 1,067 patients, Friedlander et al. (26) evaluated patients who had undergone BNS and non-BNS RARP according to continence and oncologic outcomes. Higher continence rates were reported in patients who had undergone BNS surgery, without compromising oncologic outcomes (HR, 1.69; 95\% CI, 1.43-1.99; $\mathrm{P}<0.001$ ) (26).

The best evidence for BNS comes from the study by Nyarangi-Dix where 208 men were randomized to BNS $v s$. no BNS. Although this study also included some men who underwent open RP, they demonstrated improvements in urinary continence in the BNS group $(84.2 \%$ vs. $55.3 \%$ at 3 months, $89.5 \%$ vs. $74.8 \%$ at 6 and $94.7 \%$ vs. $81.4 \%$ at 12 months in addition to higher quality of life scores at all time points, compared to non BNS patients, with no difference in positive surgical margin rates (27). Further, a recent meta-analysis involving 13 studies and 2,284 patients, BNS had better early continence rates (6 months: OR, 1.66; $\mathrm{P}=0.001)$ and long-term continence outcomes (>12 months: OR, 3.99; $\mathrm{P}=0.0002$ ) compared to non-BNS without compromising oncological outcomes. Moreover, urethral stricture formation was less likely in patients who had undergone the BNS technique (OR, 0.49; $\mathrm{P}=0.006$ ) (28) (Table 1). Further, BNS technique could also be performed with posterior reconstruction to achieve favorable outcomes and early continence rate $(4,39)$. However, these improvements in continence by BNS were not seen in all studies, with one study suggests that efforts to aggressively spare bladder neck may only increase the surgical margin positivity without advantage for continence recovery (40). As such, it is prudent to take into account disease factors such as size and location of the tumor as well as surgeon's experience in planning for BNS.

\section{Retzius-sparing technique}

The Retzius-sparing technique, first described by Galfano et al. (41) in 2010, is also called the Bocciardi approach and typically mimics the open perineal approach. This involves passing through the anterior surface of the Douglas space to reach the prostatic apex in a completely inter- or intrafascial plane without dissecting the anterior compartment, and bluntly dissecting the anterior surface of the prostate away from the Santorini plexus (Figure 2) (Video 1, Part-2, min 12:51-19:40). Therefore this preserves the endopelvic fascia, puboprostatic ligaments, and Santorini plexus, which contribute to the maintenance of postoperative continence and potency. In the initial study, Galfano et al. (41) highlighted the technique's main advantage of achieving an $>90 \%$ early continence rate by preserving the anatomical structures as much as possible, independent of the learning curve.

A recent randomized controlled trial compared the standard anterior approach of RALP with Retzius-sparing technique, validating the findings by Galfano et al. (42). Patients undergoing the Retzius-sparing technique had higher rates of complete continence $(71 \% v s .48 \%)$ at 1 week after catheter removal, lower 24-hour pad weights and an earlier time to continence compared to those undergoing the standard approach. In addition, urinary function-related bother scores at 1 and 2 weeks and at 1 month in the posterior approach were significantly lower than were scores in the anterior approach (43).

In 2019, a systematic meta-analysis of 11 studies with Retzius-sparing surgery in 751 patients further demonstrated, that this technique achieved continence faster than did patients who had undergone conventional surgery, higher complete continence rates (zero pad) with no difference in positive surgical margins or complication rates (30) (Table 1). In addition to early continence recovery and preservation of anatomical structures with Retziussparing RARP, higher continence recovery was seen up to 12 months (29). Besides these advantages, some points regarding this technique are still unresolved, including the long learning curve and the applicability of the technique to challenging cases (44) (Table 1).

\section{High nerve release technique}

The classic nerve-sparing RARP technique involves the dissection of neurovascular bundles (NVBs) from the posterolateral arc between the prostate and Denonvilliers' fascia (45). After the posterolateral course of NVBs to the prostate was described by Walsh and Donker, a number of studies have been conducted to understand the anatomical localization of the nerves and improve functional outcomes after RARP.

Recent studies indicated that the course of NVBs is much more variable than previously suggested and are 


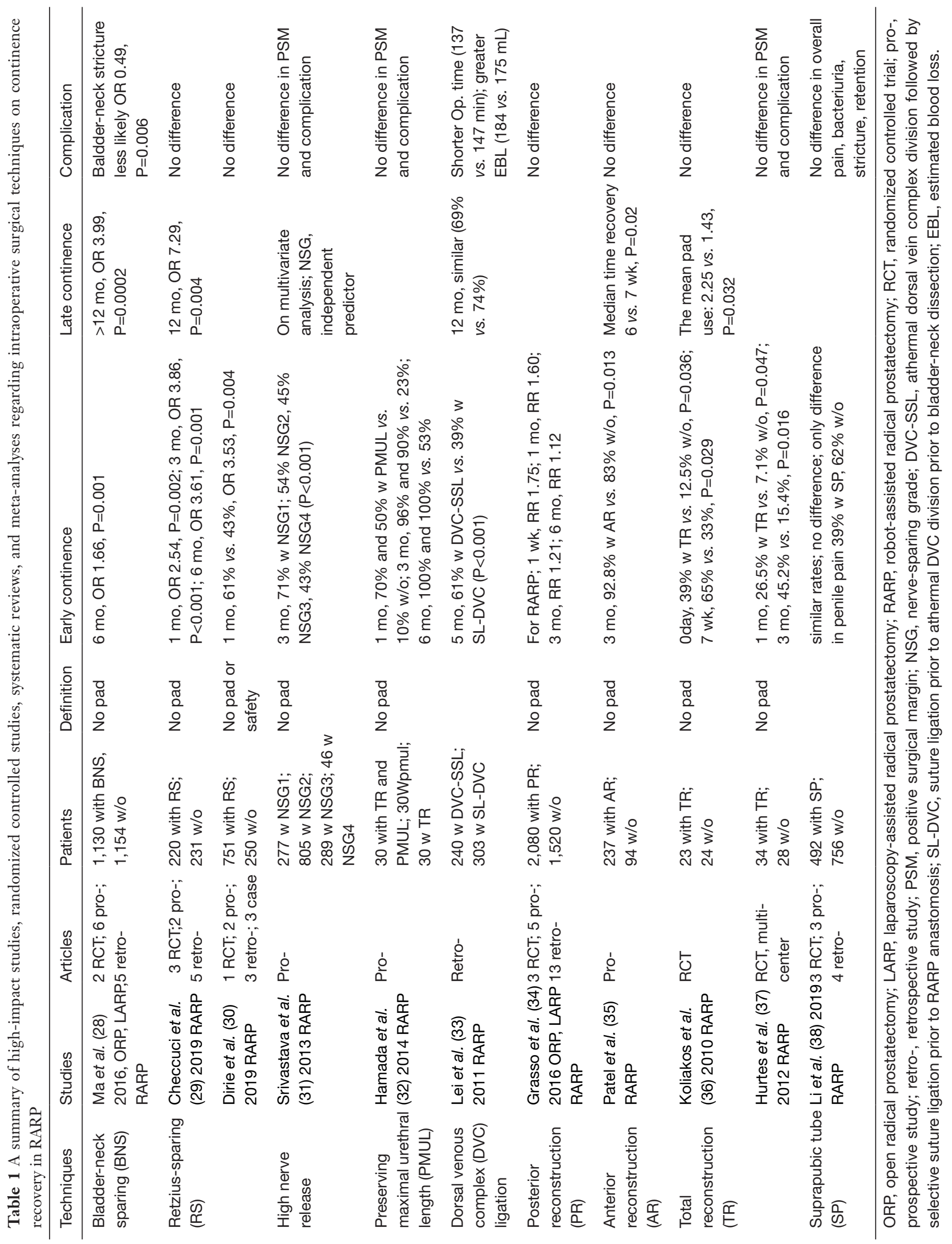



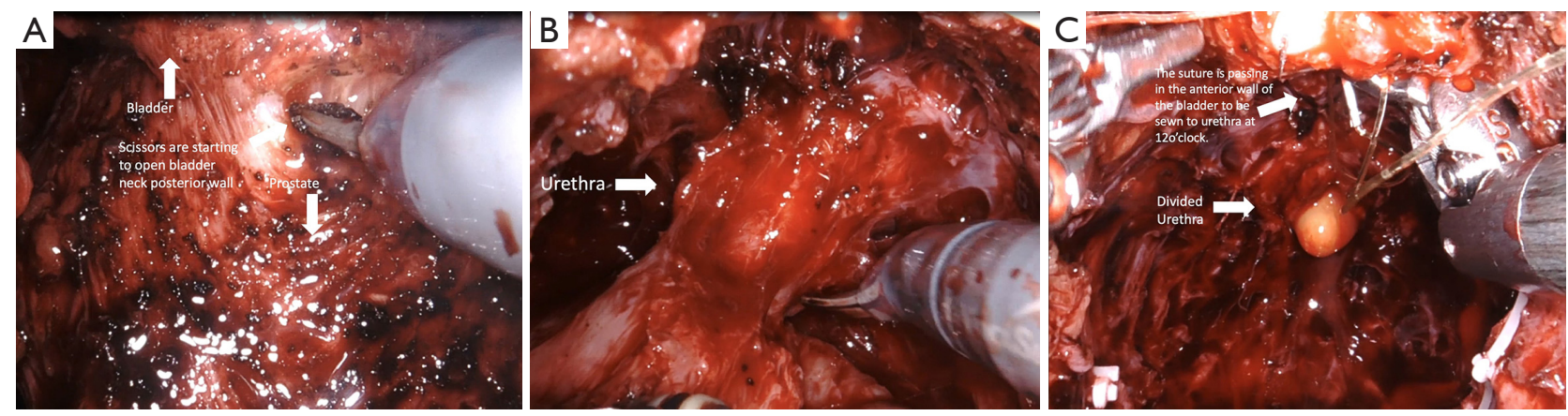

Figure 2 Retzius sparing technique. (A) Bladder neck, the urinary bladder is not dropped; staying very close to the prostate throughout its mobilization with dissection in an inter- or intrafascial plane. (B) Urethra, the anterior Retzius space is kept intact; the endopelvic fascia and puboprostatic ligaments are preserved; (C) anastomosis.

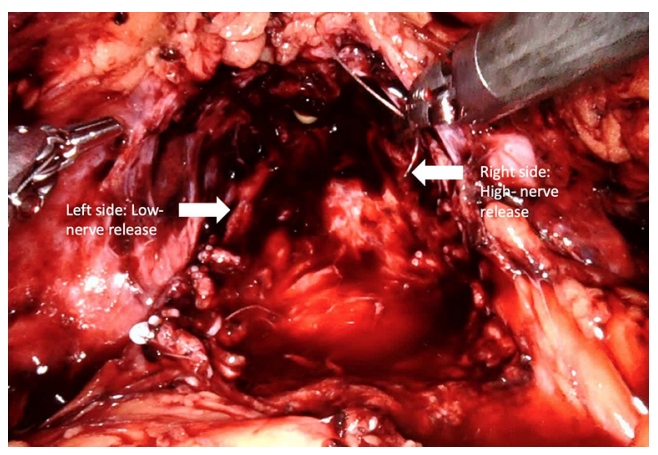

Figure 3 High nerve release. Intrafascial/interfascial dissection between the 1 o'clock and 5 o'clock positions for the right side and between the 6 o'clock and 11 o'clock positions for the left side.

primarily located either on the anterior surface of the prostate or in the posterolateral region (NVBs) (46-48). Further, the number of nerves located anteriorly increases $6 \%$ to $11.2 \%$ from the base to apex (49). As such, a high nerve release technique, also referred to as Veil of Aphrodite, was suggested to improve functional outcomes $(50,51)$. This procedure proposes intrafascial/interfascial dissection between the 1 o'clock and 5 o'clock positions for the right side and between the 6 o'clock and 11o'clock positions for the left side (Figure 3). Ghani et al. (52) then modified this technique and suggested the preservation of tissue between the 11o'clock and 1 o'clock positions, including pubovesical ligaments. This procedure (super veil) was more challenging than the standard one, so it was offered for patients in the low-risk group (Video 1, Part-1).

In their prospective study, which included 154 consecutive patients, Kaul et al. (51) reported that $29 \%$ of patients were continent at the time of catheter removal,
$97 \%$ were continent at 12 -month follow-up, and the median time to continence (zero pad) was 14 days. Thus, they concluded that the Veil of Aphrodite technique may provide early gaining of incontinence (51).

Srivastava et al. (31) reported that performing a highlevel nerve-sparing approach was an independent predictor of early continence (no pad use at 3 months). Concerning oncological outcomes, the learning curve for this technique, and the lack of randomized controlled trials, some authors suggested that standard nerve-sparing surgery might be more appropriate than the Veil of Aphrodite technique in terms of preserving functional outcomes (53) (Table 1). Since it is difficult to recognize the difference between standard nerve-sparing surgery and sparing of supportive tissues related to NVBs, nerve-sparing grading systems have been proposed and are being used by some surgeons $(54,55)$. Recent literature has suggested that sparing supporting tissues, anterior and lateral fascia, and posterolateral NVBs as much as possible provides better early continence recovery. However, this advantage may not be longterm. Therefore, in deciding on the type of nerve-sparing surgery, preoperative multiparametric magnetic resonance imaging (mpMRI) images and biopsy tumor maps should be seriously evaluated in order to secure favorable oncological outcomes (5).

\section{Preserving maximal urethral length}

Preoperative membranous urethral length (MUL) is associated with postoperative continence rates and time to continence recovery $(10,56)$. The continence rates achieved by preservation of maximal MUL was superior to the combination of posterior urethral reconstruction 
and anterior bladder suspension (32). Moreover, in a meta-analysis, Mungovan et al. (57) demonstrated that each extra millimeter of urethral length, which was measured preoperatively via MRI, was associated with early continence recovery. In keeping with these studies, Song et al. (58) showed that preoperative and postoperative MUL were significantly associated with urinary continence at 6 and 12 months after RARP. MUL is also an important predictor for continence recovery at 1,3 , and 12 months after surgery (59).

Full functional length urethral preservation (Figure 4) (Video 1, both, Part-1 and 2) can be achieved through an individualized apical dissection and careful blunt dissection of intraprostatically located urethra between the prostatic apex and colliculus seminalis since a significant part of

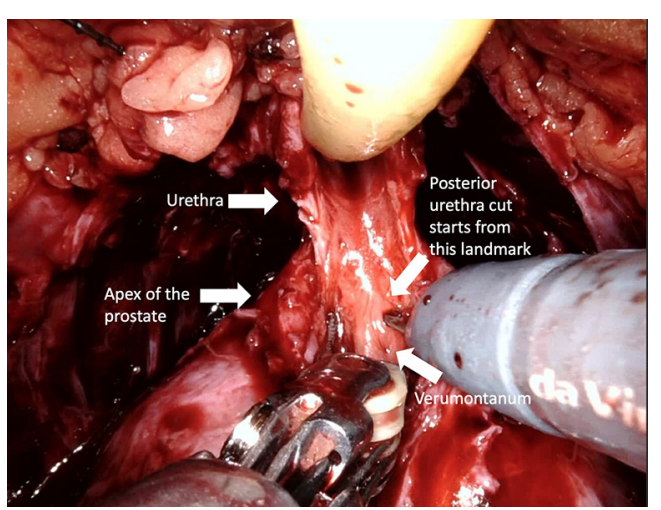

Figure 4 Preserving maximal urethral length. A maximal length of the membranous urethra is obtained by careful blunt dissection of intraprostatically located urethra since significant part of urethral sphincter is located intraprostatically. urethral sphincter is located intraprostatically (60). With this technique, $50 \%$ of patients achieved full continence at 1 week after catheter removal.

\section{Dorsal venous complex ligation}

Control of the dorsal venous complex (DVC) is one of the key steps of RARP (Figure 5) (Video 1, Part-1), since it affects blood loss, appropriate apical dissection, and therefore postoperative continence. According to the European Association of Urology Robotic Urology Section (ERUS) survey conducted in 2012, 90.5\% of surgeons who participated in the questionnaire declared that they manage the DVC by selective sutures instead of by stapler ligation and energy usage (61).

Lei et al. (33) described a selective suture ligation technique and compared the outcomes of 240 patients who underwent athermal DVC division followed by selective suture ligation prior to RARP anastomosis and 303 patients treated with suture ligation prior to athermal DVC division and bladder-neck dissection. Although continence rates were similar at 12 months after RARP, athermal DVC division followed by selective suture ligation showed better results at 5 months postoperatively (61\% vs. 39\%) (Table 1 ).

In another study, authors presented functional outcomes of patients who had undergone RARP with suture $v$. endovascular staple ligation of the DVC. There were no statistically significant differences between groups in terms of complete continence rates ( $63 \%$ vs. 55\%) (62).

In a very recent prospective study, de Carvalho et al. (63) proposed a modified technique that preserves the nerves, endopelvic fascia, and dorsal vascular complex with use
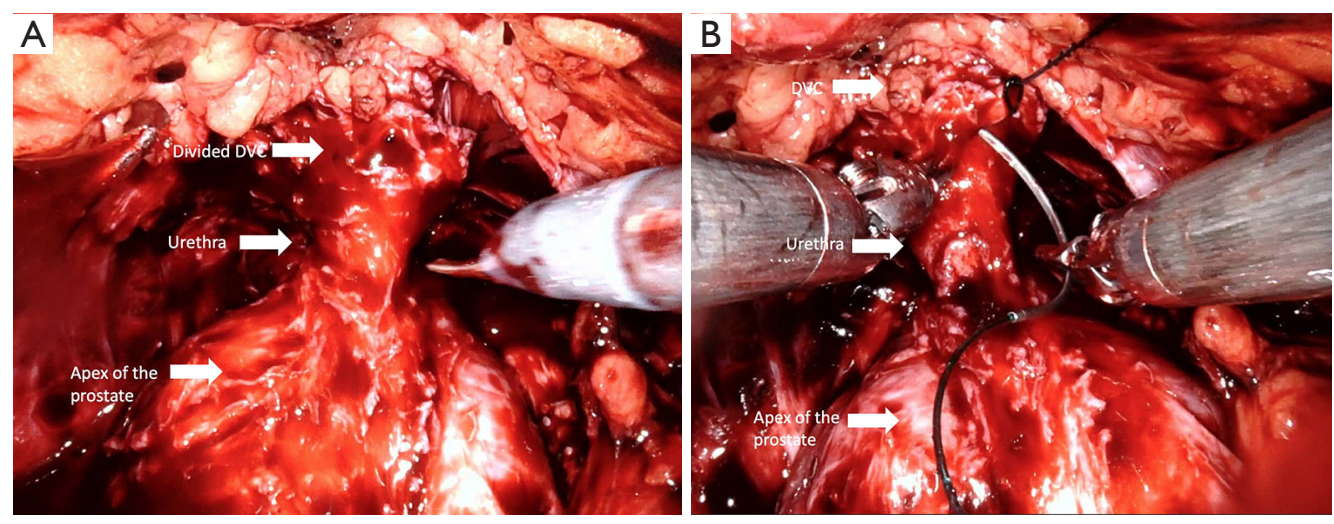

Figure 5 Dorsal venous control (DVC). (A) Athermal DVC division before suturing; (B) DVC suturing. After hanging anteriorly located periurethral supportive tissues to the periosteum of the pubic bone and back through the DVC for ligation. 


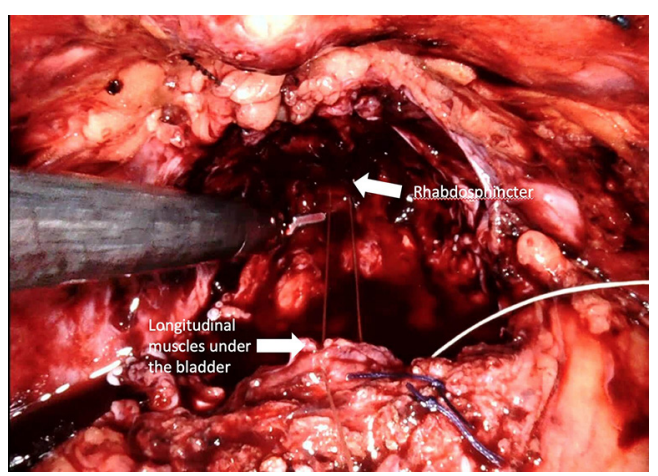

Figure 6 Posterior reconstruction (modified "Rocco" stitch). Approximation of the longitudinal muscles that lie dorsal to the bladder and the urethra (rhabdosphincter) to provide a tension-free vesico-urethral anastomosis and support the urethra-sphincteric complex. This tied stitch removes anastomotic tension in $<2$ minutes.

of a retrograde approach. In addition, they performed periurethral suspension stitch and posterior reconstruction in all cases. They reported immediate continence rates of $85.9 \%$ and $98.4 \%$, respectively, at 1 year after RARP. The median time to continence recovery was 7 days (63).

\section{Posterior reconstruction (Rocco Stitch)}

Posterior reconstruction (PR) is the approximation and suturing of the posterior layer of the rhabdosphincter to the Denonvilliers' fascia and to the posterior surface of the bladder before the vesico-urethral anastomosis is completed (Figure 6) (Video 1, Part-1). For the first time in 2001, Rocco et al. (64) presented a technique to maintain the early recovery of incontinence after open retropubic prostatectomy as a modification of the Walsh technique. Then Rocco et al. (65) adapted the technique to laparoscopy-assisted prostatectomy to decrease the time to continence recovery.

Posterior reconstruction has two basic aims: The first is the approximation of the Denonvilliers' fascia to the posterior aspect of the rhabdosphincter and posterior median raphe and thus approximation of the urethral sphincter cranially. The second is fixation of the Denonvilliers' fascia to the posterior wall of the bladder, which reduces tension in the anastomosis and provides pelvic support to the bladder neck. One of the key points for the successful performance of this technique is preservation of the Denonvilliers' fascia as much as possible during the dissection between the prostate and rectum. Another important point of this technique is exclusion of the urethra and the lateral NVBs from the reconstruction sutures.

In 2008, Coughlin et al. (66) applied a continuous suture technique in two steps for PR in RARP. In 2010, the same group modified their technique and applied a two-fold continuous suture technique in PR and reported that suturing the posterior urethra was effective in achieving early continence (67). Studies have reported higher rates of continence in the early postoperative period (1 month) in patients undergoing PR after RARP (68-70). In addition, Jeong et al. (71) reported significantly higher continence rates in postoperative months 1,3 , and 6 in patients with $\mathrm{PR}$, compared with the non-reconstructed standard group.

In 2012, Rocco et al. (72) published a systematic review on PR after RARP, in which they reported that PR improves early urinary recovery (within 30 days) and decreases the urinary leakage rate on cystography. However, this metaanalyses had some limitations, including a variety of techniques and small samples in the studies included in the review.

Grasso et al. (34) conducted an updated systematic review, in which the effect of PR on incontinence was evaluated according to the surgical approach. For RARP, there was a significant advantage of the PR technique in early and late continence with no differences in perioperative and postoperative complications with PR (Table 1).

Yet in the ERUS conducted a survey of 116 surgeons $51.7 \%$ declared that they usually perform posterior reconstruction; $28.4 \%$ of them never perform this procedure (61).

\section{Anterior retropubic suspension (Patel stitch)}

The periurethral retropubic suspension stitch was first described by Walsh (73) in an open retropubic prostatectomy; then Patel et al. (35) adapted this technique, which proposes the suspension of rhabdosphincter in pubic periosteum with puboprostatic ligaments in a figure eight configuration after ligation of DVC into RARP (Figure 7) (Video 1, Part-1). Patel et al. (35) reported outcomes of their 331 consecutive patients: 237 with the suspension stitch and of 94 without the stitch showing a significant difference in continence only at month 3 after RARP (zero pad, $83 \% v s$. $92.8 \%$ ) with a shorter time to incontinence recovery with a suspension stitch (Table 1).

In a very recent study, a significant difference in complete continence (zero pad) rate at the time of catheter removal and at 6 months after RARP was reported with 


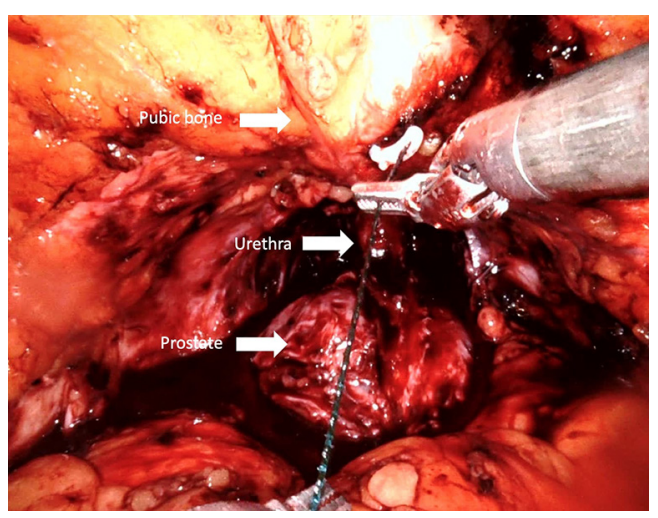

Figure 7 Periurethral anchor stitch ("Patel" stitch). The urethra is stabilized by anchoring supportive tissues, dorsal venous complex and puboprostatic ligaments to the periosteum in a figure eight configuration

anterior reconstruction compared to patients without reconstruction (74). Yet, the authors advocated total anatomical reconstruction in their center combined anterior and posterior reconstruction (74).

\section{Total anatomical reconstruction}

Surgeons typically prefer using both anterior and posterior reconstruction together, rather than using one technique, to maintain early recovery of incontinence. In a randomized controlled trial, which compared the effect of both anterior and posterior reconstruction on continence recovery, the authors reported similar outcomes as those reported with use of the standard technique (no reconstruction) in terms of both very early (1-30 days after catheter removal) and late-term (average, 23.5 months) incontinence rates $(75,76)$. In contrast, in two randomized controlled trials, Koliakos et al. (36) and Hurtes et al. (37) reported significant improvement in early continence recovery in patients with combined anterior and posterior reconstruction compared with classic Van Velthoven anastomosis only (Table 1).

A number of other total reconstructive techniques have resulted in improved continence rates. Tewari et al. (77) reported a complete continence rate of $60.9 \%$ at 6 weeks postoperatively in patients with a combination of apical urethral dissection, detrusor trigonoplasty, and suprapubic tube placement in addition to total reconstruction. Kojima et al. (78) developed a technique that involves suture fixation of the bladder neck to pubic bone; they performed this technique in 27 patients and reported significant early continence rates compared with rates in 30 patients who were not treated with this procedure.

Porpiglia et al. (79) described a total anatomical reconstruction technique in 252 consecutive patients, which consisted of three layers of posterior reconstruction and two layers of anterior reconstruction with complete anatomical restoration of periurethral tissues, and reported the continence rates of $98 \%$ at 24 weeks after RARP. The outcomes on urinary continence recovery after 1,000 procedures with total anatomical reconstruction technique were later reported achieving complete continence $94 \%$ at 48 weeks (80).

\section{Suprapubic tube}

Urethral catheters permit urinary drainage post RARP and allows healing of the anastomosis. Traditionally it was thought that transurethral catheters also prevent anastomotic stricture development after RARP (81). Despite the short catheterization time in RARP compared to open radical prostatectomy many patients who receive transurethral catheters after surgery feel discomfort (82). In 2008, Tewari et al. (83) introduced a urethral catheterless technique for RARP using a custom-made suprapubic catheter along with an anastomotic splint demonstrating lower levels discomfort and an earlier return to continence. Subsequently, a number of studies were conducted to compare postoperative discomfort, pain, and functional outcomes between transurethral and suprapubic catheters.

Harke et al. (84) performed a randomized controlled trial that included 160 patients. For the suprapubic catheter group, they used an additional suprapubic catheter and removed the transurethral catheter on postoperative day 1 . In terms of median pain scores of postoperative days 1-4, Harke et al. reported a significant difference between the two groups (2.4 points in the transurethral catheter group, and 1.3 points in the suprapubic catheter group). Moreover, they found no significant difference in postoperative bacteriuria, bladder neck stricture and complications, or incontinence rates at 22 months of follow-up (84).

In a study by Sammon et al. (85) of 1,270 patients, $17.3 \%$ of whom never used a pad after catheter removal, the researchers concluded that performing nerve-sparing surgery and placing a suprapubic tube for postoperative bladder emptying were independent predictors of early continence recovery after RARP.

In a very recent systematic meta-analysis that included 10 studies, 3 of which were randomized controlled trials that included 1,248 men, the authors compared transurethral 
and suprapubic catheters in terms of overall and penile pain, complications, and functional outcomes. They reported no statistically significant differences between the two groups regarding overall pain, urinary incontinence, and complications that included bladder neck and anastomotic stricture, bacteriuria, and urinary retention; the only significant differences in penile pain were noted after RARP (39\% of patients with suprapubic catheter $v s .62 \%$ of patients with transurethral catheter). The authors concluded that compared with transurethral catheter placement, suprapubic catheter placement may be associated with less penile pain and increased comfort without an effect on postoperative complications or incontinence rates (38) (Table 1).

\section{Discussion points}

In this narrative/highlights review, we present many of the concepts surgeons have studied in relation to continence preserving surgical technique. There are certainly multiple limitations apparent in this topic including varying definitions of continence or surveys utilized, little data on technique generalizations, and very little head to head/ randomized type of study designs. Most studies introduce a novel idea, and compare it to the most recent technique utilized, i.e., non-controlled/historical comparisons. Furthermore, it is hard to know the effects of utilizing multiple of these techniques in the same case.

Are there common themes apparent? We can identify at least three: (I) it seems as though many techniques that preserve anterior support for the bladder are helpfulRetzius sparing, pubic bone stitch, SP tube, etc.; (II) anterior and other nerve sparing techniques may have a mild effect, and (III) "less radical" dissection planes that preserve more urethra and more bladder neck tissue to reconstruct and maintain urethral coaptation. Therefore, the concepts of continence preservation cross over multiple etiologies including the nerve supply to the urethra, vasculature, tissue support, and bladder position. Ultimately, the surgeon must decide which of these techniques are safe, feasible, and maintain the oncologic goals of the procedure.

In conclusion, post RARP continence depends on multiple factors including pre-operative patient and tumor factors and surgical factors. While a number of these factors are non-modifiable, there are a number of surgical techniques, which can improve continence post RARP. Therefore attention should be focused on developing and utilizing these techniques when performing RARP, especially in men with high risk of developing incontinence.

\section{Acknowledgments}

Funding: None.

\section{Footnote}

Provenance and Peer Review: This article was commissioned by the Guest Editor (Shomik Sengupta) for the series "Surgery for Urologic Cancers" published in Translational Andrology and Urology. The article has undergone external peer review.

Conflicts of Interest: All authors have completed the ICMJE uniform disclosure form (available at http://dx.doi. org/10.21037/tau.2020.03.36). The series "Surgery for Urologic Cancers" was commissioned by the editorial office without any funding or sponsorship. The authors have no conflicts of interest to declare.

Ethical Statement: The authors are accountable for all aspects of the work in ensuring that questions related to the accuracy or integrity of any part of the work are appropriately investigated and resolved.

Open Access Statement: This is an Open Access article distributed in accordance with the Creative Commons Attribution-NonCommercial-NoDerivs 4.0 International License (CC BY-NC-ND 4.0), which permits the noncommercial replication and distribution of the article with the strict proviso that no changes or edits are made and the original work is properly cited (including links to both the formal publication through the relevant DOI and the license). See: https://creativecommons.org/licenses/by-nc-nd/4.0/.

\section{References}

1. Yaxley JW, Coughlin GD, Chambers SK, et al. Robotassisted laparoscopic prostatectomy versus open radical retropubic prostatectomy: early outcomes from a randomised controlled phase 3 study. Lancet 2016;388:1057-66.

2. Ficarra V, Novara G, Rosen RC, et al. Systematic review and meta-analysis of studies reporting urinary continence recovery after robot-assisted radical prostatectomy. Eur Urol 2012;62:405-17.

3. Clark JA, Inui TS, Silliman RA, et al. Patients' perceptions of quality of life after treatment for early prostate cancer. J Clin Oncol 2003;21:3777-84. 
4. Vis AN, van der Poel HG, Ruiter AEC, et al. Posterior, Anterior, and Periurethral Surgical Reconstruction of Urinary Continence Mechanisms in Robot-assisted Radical Prostatectomy: A Description and Video Compilation of Commonly Performed Surgical Techniques. Eur Urol 2019;76:814-22.

5. Pavlovich CP, Rocco B, Druskin SC, et al. Urinary continence recovery after radical prostatectomy anatomical/reconstructive and nerve-sparing techniques to improve outcomes. BJU Int 2017;120:185-96.

6. Rajih E, Meskawi M, Alenizi AM, et al. Perioperative predictors for post-prostatectomy urinary incontinence in prostate cancer patients following robotic-assisted radical prostatectomy: Long-term results of a Canadian prospective cohort. Can Urol Assoc J 2019;13:E125-31.

7. Tan G, Srivastava A, Grover S, et al. Optimizing vesicourethral anastomosis healing after robot-assisted laparoscopic radical prostatectomy: lessons learned from three techniques in 1900 patients. J Endourol 2010;24:1975-83.

8. Shao IH, Chang YH, Hou CM, et al. Predictors of shortterm and long-term incontinence after robot-assisted radical prostatectomy. J Int Med Res 2018;46:421-9.

9. Novara G, Ficarra V, D'Elia C, et al. Evaluating urinary continence and preoperative predictors of urinary continence after robot assisted laparoscopic radical prostatectomy. J Urol 2010;184:1028-33.

10. Grivas N, van der Roest R, Tillier C, et al. Patterns of Benign Prostate Hyperplasia Based on Magnetic Resonance Imaging Are Correlated With Lower Urinary Tract Symptoms and Continence in Men Undergoing a Robot-assisted Radical Prostatectomy for Prostate Cancer. Urology 2017;107:196-201.

11. Shikanov S, Desai V, Razmaria A, et al. Robotic radical prostatectomy for elderly patients: probability of achieving continence and potency 1 year after surgery. J Urol 2010;183:1803-7.

12. Ikarashi D, Kato Y, Kanehira M, et al. Appropriate preoperative membranous urethral length predicts recovery of urinary continence after robot-assisted laparoscopic prostatectomy. World J Surg Oncol 2018;16:224.

13. Coelho RF, Chauhan S, Guglielmetti GB, et al. Does the presence of median lobe affect outcomes of robotassisted laparoscopic radical prostatectomy? J Endourol 2012;26:264-70.

14. Mustafa M, Davis JW, Gorgel SN, et al. Robotic or Open Radical Prostatectomy in Men with Previous Transurethral Resection of Prostate. Urol J 2017;14:2955-60.
15. Gontero P, Marra G, Alessio P, et al. Salvage Radical Prostatectomy of Recurrent Prostate Cancer: Morbidity and Functional Outcomes from a Large Multicenter Series of Open versus Robotic Approaches. J Urol 2019;202:725-31.

16. Chen J, Chu T, Ghodoussipour S, et al. Effect of surgeon experience and bony pelvic dimensions on surgical performance and patient outcomes in robot-assisted radical prostatectomy. BJU Int 2019;124:828-35.

17. Cakmak S, Canda AE, Ener K, et al. Does Type 2 Diabetes Mellitus Have an Impact on Postoperative Early, Mid-Term and Late-Term Urinary Continence After Robot-Assisted Radical Prostatectomy? J Endourol 2019;33:201-6.

18. Samadi DB, Muntner P, Nabizada-Pace F, et al. Improvements in robot-assisted prostatectomy: the effect of surgeon experience and technical changes on oncologic and functional outcomes. J Endourol 2010;24:1105-10.

19. Chen J, Cheng N, Cacciamani G et al. Objective assessment of robotic surgical technical skill: a systemic review. J Urol 2019;201:461-9.

20. Goldenberg MG, Goldenberg L, Grantcharov TP. Surgeon performance predicts early continence after robot-assisted radical Prostatectomy. J Endourol 2017;31:858-63.

21. Hung AJ, Chen J, Ghodoussipour S, et al. A deep-learning model using automated performance metrics and clinical features to predict urinary continence recovery after robotassisted radical prostatectomy. BJU Int 2019;124:487-95.

22. Reeves F, Preece P, Kapoor J, et al. Preservation of the neurovascular bundles is associated with improved time to continence after radical prostatectomy but not long-term continence rates: results of a systematic review and metaanalysis. Eur Urol 2015;68:692-704.

23. Preisser F, Pompe RS, Salomon G, et al. Impact of the estimated blood loss during radical prostatectomy on functional outcomes. Urol Oncol 2019;37:298.e11-298.e17.

24. Zattoni F, Artibani W, Patel V, et al. Technical innovations to optimize continence recovery after robotic assisted radical prostatectomy. Minerva Urol Nefrol 2019;71:324-38.

25. Freire MP, Weinberg AC, Lei Y, et al. Anatomic bladder neck preservation during robotic-assisted laparoscopic radical prostatectomy: description of technique and outcomes. Eur Urol 2009;56:972-80.

26. Friedlander DF, Alemozaffar M, Hevelone ND, et al. Stepwise description and outcomes of bladder neck sparing during robot-assisted laparoscopic radical prostatectomy. J 
Urol 2012;188:1754-60.

27. Nyarangi-Dix JN, Radtke JP, Hadaschik B, et al. Impact of complete bladder neck preservation on urinary continence, quality of life and surgical margins after radical prostatectomy: a randomized, controlled, single blind trial. J Urol 2013;189:891-8.

28. Ma X, Tang K, Yang C, et al. Bladder neck preservation improves time to continence after radical prostatectomy: a systematic review and meta-analysis. Oncotarget 2016;7:67463-75.

29. Checcucci E, Veccia A, Fiori C, et al. Retzius-sparing robot-assisted radical prostatectomy vs the standard approach: a systematic review and analysis of comparative outcomes. BJU Int 2020;125:8-16.

30. Dirie NI, Pokhrel G, Guan W, et al. Is Retzius-sparing robot-assisted radical prostatectomy associated with better functional and oncological outcomes? Literature review and meta-analysis. Asian J Urol 2019;6:174-82.

31. Srivastava A, Chopra S, Pham A, et al. Effect of a riskstratified grade of nerve-sparing technique on early return of continence after robot-assisted laparoscopic radical prostatectomy. Eur Urol 2013;63:438-44.

32. Hamada A, Razdan S, Etafy MH, et al. Early return of continence in patients undergoing robot-assisted laparoscopic prostatectomy using modified maximal urethral length preservation technique. J Endourol 2014;28:930-8.

33. Lei Y, Alemozaffar M, Williams SB, et al. Athermal division and selective suture ligation of the dorsal vein complex during robot-assisted laparoscopic radical prostatectomy: description of technique and outcomes. Eur Urol 2011;59:235-43.

34. Grasso AA, Mistretta FA, Sandri M, et al. Posterior musculofascial reconstruction after radical prostatectomy: an updated systematic review and a meta-analysis. BJU Int 2016;118:20-34.

35. Patel VR, Coelho RF, Palmer KJ, et al. Periurethral suspension stitch during robot-assisted laparoscopic radical prostatectomy: description of the technique and continence outcomes. Eur Urol 2009;56:472-8.

36. Koliakos N, Mottrie A, Buffi N, et al. Posterior and anterior fixation of the urethra during robotic prostatectomy improves early continence rates. Scand J Urol Nephrol 2010;44:5-10.

37. Hurtes X, Roupret M, Vaessen C, et al. Anterior suspension combined with posterior reconstruction during robot-assisted laparoscopic prostatectomy improves early return of urinary continence: a prospective randomized multicentre trial. BJU Int 2012;110:875-83.

38. Li MX, Cheng P, Yao L, et al. Suprapubic tube compared with urethral catheter drainage after robot-assisted radical prostatectomy: A systematic review and meta-analysis. Asian J Surg 2019;42:71-80.

39. Bartoletti R, Mogorovich A, Francesca F, et al. Combined bladder neck preservation and posterior musculofascial reconstruction during robotic assisted radical prostatectomy: effects on early and long term urinary continence recovery. BMC Urol 2017;17:119.

40. Tyson MD 2nd, Ark J, Gregg JR, et al. The Null Effect of Bladder Neck Size on Incontinence Outcomes after Radical Prostatectomy. J Urol 2017;198:1404-8.

41. Galfano A, Ascione A, Grimaldi S, et al. A new anatomic approach for robot-assisted laparoscopic prostatectomy: a feasibility study for completely intrafascial surgery. Eur Urol 2010;58:457-61.

42. Galfano A, Di Trapani D, Sozzi F, et al. Beyond the learning curve of the Retzius-sparing approach for robotassisted laparoscopic radical prostatectomy: oncologic and functional results of the first 200 patients with $\geq 1$ year of follow-up. Eur Urol 2013;64:974-80.

43. Dalela D, Jeong W, Prasad MA, et al. A Pragmatic Randomized Controlled Trial Examining the Impact of the Retzius-sparing Approach on Early Urinary Continence Recovery After Robot-assisted Radical Prostatectomy. Eur Urol 2017;72:677-85.

44. Stonier T, Simson N, Davis J, et al. Retzius-sparing robot-assisted radical prostatectomy (RS-RARP) vs standard RARP: it's time for critical appraisal. BJU Int 2019;123:5-7.

45. Lepor H. Radical retropubic prostatectomy. Urol Clin North Am 2001;28:509-19.

46. Eichelberg C, Erbersdobler A, Michl U, et al. Nerve distribution along the prostatic capsule. Eur Urol 2007;51:105-10.

47. Takenaka A, Murakami G, Matsubara A, et al. Variation in course of cavernous nerve with special reference to details of topographic relationships near prostatic apex: histologic study using male cadavers. Urology 2005;65:136-42.

48. Sievert KD, Hennenlotter J, Laible I, et al. The periprostatic autonomic nerves--bundle or layer? Eur Urol 2008;54:1109-16.

49. Clarebrough EE, Challacombe BJ, Briggs C, et al. Cadaveric analysis of periprostatic nerve distribution: an anatomical basis for high anterior release during radical prostatectomy? J Urol 2011;185:1519-25.

50. Lunacek A, Schwentner C, Fritsch H, et al. Anatomical 
radical retropubic prostatectomy: 'curtain dissection' of the neurovascular bundle. BJU Int 2005;95:1226-31.

51. Kaul S, Savera A, Badani K, et al. Functional outcomes and oncological eficacy of Vattikuti Institute prostatectomy with Veil of Aphrodite nerve-sparing: an analysis of 154 consecutive patients. BJU Int 2006;97:467-72.

52. Ghani KR, Trinh QD, Menon M. Vattikuti Institute Prostatectomy-Technique in 2012. J Endourol 2012;26:1558-65.

53. Murphy DG, Costello AJ. High prostatic fascia release or standard nerve sparing? A viewpoint from the Royal Melbourne Hospital. J Robot Surg 2008;2:181-5.

54. Schatloff O, Chauhan S, Sivaraman A, et al. Anatomic grading of nerve sparing during robot-assisted radical prostatectomy. Eur Urol 2012;61:796-802.

55. Tewari AK, Srivastava A, Huang MW et al. Anatomical grades of nerve sparing: a risk-stratified approach to neural-hammock sparing during robot-assisted radical prostatectomy (RARP). BJU Int 2011;108:984-92.

56. Nguyen L, Jhaveri J, Tewari A. Surgical technique to overcome anatomical shortcoming: balancing postprostatectomy continence outcomes of urethral sphincter lengths on preoperative magnetic resonance imaging. J Urol 2008;179:1907-11.

57. Mungovan SF, Sandhu JS, Akin O, et al. Preoperative Membranous Urethral Length Measurement and Continence Recovery Following Radical Prostatectomy: A Systematic Review and Meta-analysis. Eur Urol 2017;71:368-78.

58. Song W, Kim CK, Park BK, et al. Impact of preoperative and postoperative membranous urethral length measured by 3 Tesla magnetic resonance imaging on urinary continence recovery after robotic-assisted radical prostatectomy. Can Urol Assoc J 2017;11:E93-9.

59. Jeong SJ, Yeon JS, Lee JK, et al. Development and validation of nomograms to predict the recovery of urinary continence after radical prostatectomy: comparisons between immediate, early, and late continence. World J Urol 2014;32:437-44.

60. Schlomm T, Heinzer H, Steuber T, et al. Full functionallength urethral sphincter preservation during radical prostatectomy. Eur Urol 2011;60:320-9.

61. Ficarra V, Wiklund PN, Rochat CH, et al. The European Association of Urology Robotic Urology Section (ERUS) survey of robot-assisted radical prostatectomy (RARP). BJU Int 2013;111:596-603.

62. Wu SD, Meeks JJ, Cashy J, et al. Suture versus staple ligation of the dorsal venous complex during robot- assisted laparoscopic radical prostatectomy. BJU Int 2010;106:385-90.

63. de Carvalho PA, Barbosa JABA, Guglielmetti GB, et al. Retrograde Release of the Neurovascular Bundle with Preservation of Dorsal Venous Complex During Robotassisted Radical Prostatectomy: Optimizing Functional Outcomes. Eur Urol 2020;77:628-35.

64. Rocco F, Gadda F, Acquati P, et al. Personal research: reconstruction of the urethral striated sphincter. Arch Ital Urol Androl 2001;73:127-37.

65. Rocco B, Gregori A, Stener S, et al. Posterior reconstruction of the rhabdosphincter allows a rapid recovery of continence after transperitoneal videolaparoscopic radical prostatectomy. Eur Urol 2007;51:996-1003.

66. Coughlin G, Dangle PP, Patil NN, et al. Surgery Illustrated--focus on details. Modified posterior reconstruction of the rhabdosphincter: application to robotic- assisted laparoscopic prostatectomy. BJU Int 2008;102:1482-5.

67. Coelho RF, Chauhan S, Orvieto MA, et al. Influence of modified posterior reconstruction of the rhabdosphincter on early recovery of continence and anastomotic leakage rates after robot-assisted radical prostatectomy. Eur Urol 2011;59:72-80.

68. Woo JR, Shikanov S, Zorn KC, et al. Impact of posterior rhabdosphincter reconstruction during robot-assisted radical prostatectomy: retrospective analysis of time to continence. J Endourol 2009;23:1995-9.

69. Sutherland DE, Linder B, Guzman AM, et al. Posterior rhabdosphincter reconstruction during robotic assisted radical prostatectomy: results from a phase II randomized clinical trial. J Urol 2011;185:1262-7.

70. Joshi N, de Blok W, van Muilekom E, et al. Impact of posterior musculofascial reconstruction on early continence after robot-assisted laparoscopic radical prostatectomy: results of a prospective parallel group trial. Eur Urol 2010;58:84-9.

71. Jeong CW, Oh JJ, Jeong SJ, et al. Novel posterior reconstruction technique during robot-assisted laparoscopic prostatectomy: description and comparative outcomes. Int J Urol 2012;19:683-7.

72. Rocco B, Cozzi G, Spinelli MG, et al. Posterior musculofascial reconstruction after radical prostatectomy: a systematic review of the literature. Eur Urol 2012;62:779-90.

73. Walsh PC. Anatomical radical prostatectomy: evolution of the surgical technique. J Urol 1998;160:2418-24. 
74. Puliatti S, Elsherbiny A, Eissa A, et al. Effect of puboprostatic ligament reconstruction on continence recovery after robot-assisted laparoscopic prostatectomy: our initial experience. Minerva Urol Nefrol 2019;71:230-9.

75. Menon M, Muhletaler F, Campos M, et al. Assessment of early continence after reconstruction of the periprostatic tissues in patients undergoing computer assisted (robotic) prostatectomy: results of a 2 group parallel randomized controlled trial. J Urol 2008;180:1018-23.

76. Sammon JD, Muhletaler F, Peabody JO, et al. Long-term functional urinary outcomes comparing single- vs doublelayer urethrovesical anastomosis: two-year follow-up of a two-group parallel randomized controlled trial. Urology 2010;76:1102-7.

77. Tewari AK, Ali A, Ghareeb G, et al. Improving time to continence after robot-assisted laparoscopic prostatectomy: augmentation of the total anatomic reconstruction technique by adding dynamic detrusor cuff trigonoplasty and suprapubic tube placement. J Endourol 2012;26:1546-52.

78. Kojima Y, Hamakawa T, Kubota Y, et al. Bladder neck sling suspension during robot-assisted radical prostatectomy to improve early return of urinary continence: a comparative analysis. Urology 2014;83:632-9.

79. Porpiglia F, Bertolo R, Manfredi M, et al. Total Anatomical Reconstruction During Robot-assisted Radical Prostatectomy: Implications on Early Recovery of Urinary Continence. Eur Urol 2016;69:485-95.

Cite this article as: Urkmez A, Ranasinghe W, Davis JW. Surgical techniques to improve continence recovery after robotassisted radical prostatectomy. Transl Androl Urol 2020;9(6):30363048. doi: $10.21037 /$ tau.2020.03.36
80. Manfredi M, Checcucci E, Fiori C, et al. Total anatomical reconstruction during robot-assisted radical prostatectomy: focus on urinary continence recovery and related complications after 1000 procedures. BJU Int 2019;124:477-86.

81. Morgan MS, Ozayar A, Friedlander JI, et al. An Assessment of Patient Comfort and Morbidity After Robot-Assisted Radical Prostatectomy with Suprapubic Tube Versus Urethral Catheter Drainage. J Endourol 2016;30:300-5.

82. Sammon JD, Trinh QD, Sukumar S, et al. Long-term follow-up of patients undergoing percutaneous suprapubic tube drainage after robot-assisted radical prostatectomy (RARP). BJU Int 2012;110:580-5.

83. Tewari A, Rao S, Mandhani A. Catheter-less robotic radical prostatectomy using a custom-made synchronous anastomotic splint and vesical urinary diversion device: report of the initial series and perioperative outcomes. BJU Int 2008;102:1000-4.

84. Harke N, Godes M, Habibzada J, et al. Postoperative patient comfort in suprapubic drainage versus transurethral catheterization following robot-assisted radical prostatectomy: a prospective randomized clinical trial. World J Urol 2017;35:389-94.

85. Sammon JD, Sharma P, Trinh QD, et al. Predictors of immediate continence following robot-assisted radical prostatectomy. J Endourol 2013;27:442-6. 